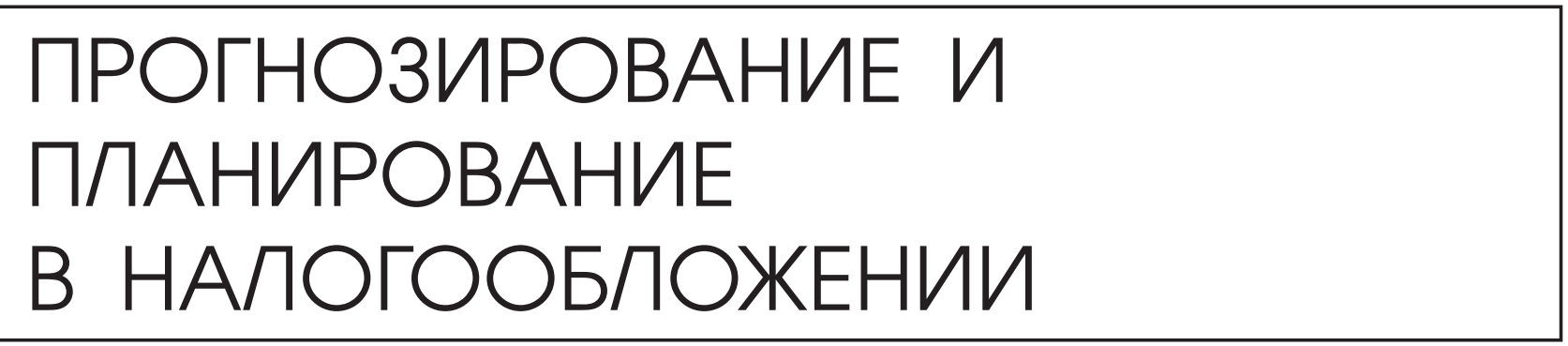

И. В. Оробинская, И. В. Гашенко

\title{
МЕХАНИЗМ ВЗАИМОДЕЙСТВИЯ ГОЛОВНОЙ КОМПАНИИ И ФИЛИАЛОВ В РАМКАХ КОНСОЛИДИРОВАННОЙ ГРУППЫ НАЛОГОПЛАТЕЛЬЩИКОВ И ЕГО ВЛИЯНИЕ НА ВЕЛИЧИНУ НАЛОГОВОГО БРЕМЕНИ
}

\begin{abstract}
Аннотация. Предметом исследования выступают экономические отношения, возникающие в процессе налогообложения сельскохозяйственных товаропроизводителей. Объектом исследования являются интегрированные структуры агропромышленного комплекса Российской Федерации. На сегодня интегрированные формирования занимают значимое место в производстве и реализаиии сельскохозяйственной продукиии РФ. Вместе с тем в настоящее время существует ряд проблем, сдерживающих эффективное и устойчивое развитие интегрированных структур на селе, среди которых следует особо выделить проблему выбора оптимальной системы налогообложения. Так, опыт показывает, что сложившаяся система налогообложения не обеспечивает выполнения всех возложенных на нее функиий, а в свете проводимой государственной политики поддержки отечественного товаропроизводителя и налоговых реформ нуждается в глубоком исследовании и корректировке. В работе использовались абстрактно-логический, монографический, статистико-экономический, и другие методы экономических исследований. Методологической основой исследования послужили фундаментальные концепции, представленные в трудах отечественных и зарубежных ученых, законодательные и нормативно-правовые акты государственных органов власти, федеральные законы, Указы Президента и Постановления Правительства РФ, материалы научно-практических конференций, затрагивающие вопросы налогообложения сельскохозяйственных товаропроизводителей. В данном исследовании рассматривается налоговое планирование интегрированных формирований агропромышленного комплекса России с точки зрения налоговой оптимизации. Научная новизна работы заключается в оценке влияния механизма взаимодействия головной компании и группы филиалов в рамках холдинговой структуры на величину налоговой нагрузки в целом.

Ключевые слова: налогообложение, налоговая нагрузка, оптимизация, сельскохозяйственные товаропроизводители, холдинги, филиаль, НДС, НДФЛ, налог на прибыль, налог на имущество.

Abstract. The subject of the research is the economic relations arising in the process of taxation of agricultural goods producers. The object of the research is the integrated structures of the agricultural sector of the Russian Federation. Today integrated establishments play an important role in the production and sale of agricultural goods in the Russian Federation. Meanwhile, there is a number of problems that hinder efficiency and sustainable development of integrated structures in the country-side. Among these problems the authors emphasize the problem of selecting the optimal system of taxation. The experience has been that the current system of taxation does not fully perform all its functions. Taking into account the ongoing state policy aimed at supporting Russian goods producers and tax reforms, it is necessary to to conduct the in-depth analysis and improvement of the current system of taxation. The authors of the research have used the abstract-logical, monographic, statistical-economical and other methods of economic research. The methodological basis of the research includes fundamental concepts that can be found in the works written by Russian and foreign scientists as well as legislative and regulatory legal acts of state authorities, federal laws, Decrees of the President and Russian Federation Government Regulations, and materials of the research and practice conferences on the issues of taxation of agricultural goods producers.
\end{abstract}




\section{Прогнозирование и планирование в налогообложении}

The authors of the present research view tax planning of intergrated establishments of the Russia's agricultural sector from the point of view of tax optimization. The scientific novelty of the research is caused by the fact that the authors evaluate the influence of the mechanism of interaction between the parent company and affiliated companies as parts of the holding on the amount of tax burden in general.

Keywords: agricultural goods producers, holdings, affiliates, value added tax, personal income tax, income tax, property tax, optimization, tax burden, taxation.

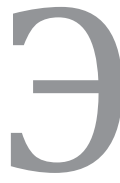

ффективность системы налогообложения в сельском хозяйстве зависит от двух составляющих: формирования налоговой политики государством через налоговое законодательство (макроуровень) и конкретная реализация данной налоговой политики на микроуровне посредством использования организациями предоставленных возможностей оптимизации налогообложения.

Мысчитаем, что все применяемые в практике хозяйствования подходы к налоговому планированию можно условно объединить в две группы. Первая группа включает в себя минимизацию налоговой нагрузки налогоплательщика. В основе второго подхода лежит налоговая оптимизация, связанная с достижением определенных пропорций в деятельности предприятия.

Сущность второго подхода заключается в том, что в большинстве случаев сельскохозяйственные товаропроизводители, в частности, интегрированные, помимо непосредственно сельскохозяйственного производства занимаются также и другими видами деятельности, например, переработкой сельскохозяйственной продукции. При этом может сложиться ситуация, при которой доля дохода от деятельности, связанной с производством, реализацией, первичной и последующей промышленной переработкой собственной продукции, не превысит 70\%. Данное предприятие не будет признаваться сельскохозяйственным товаропроизводителем на основании ст. 346.2 пп. 2 НК РФ, и оно лишится возможности применения ЕСХН. Для таких предприятий может быть целесообразным выделение производств, не связанных непосредственно с сельским хозяйством, для того чтобы основное предприятие имело возможность перехода на уплату ЕСХН.

На наш взгляд, для интегрированных формирований наиболее целесообразным является рассмотрение данного вопроса с точки зрения второго подхода, т.е. налоговой оптимизации.
Под оптимизацией налогообложения следует понимать организационные мероприятия в рамках действующего законодательства, связанные с выбором времени, места и видов деятельности, созданием и сопровождением наиболее эффективных схем и договорных взаимоотношений с целью увеличения денежных потоков компании за счет минимизации налоговых платежей.

Следует отметить, что процесс оптимизации заключается не только в снижении налогов, но и в избегании возможных штрафных санкций со стороны налоговых органов. Следовательно, налоговая оптимизация должна быть направлена не только на поиск всех возможных вариантов уменьшения налогов, но и на обоснование правильности исчисления сумм налогов, особенно в спорных ситуациях.

Таким образом, применение различных способов налоговой оптимизации позволяет достичь реального экономического эффекта в агрохолдингах.

Основываясь на проведенных теоретических и аналитических исследованиях, мы предлагаем мероприятия, направленные на совершенствование существующей системы налогообложения для сельхозтоваропроизводителей, реализация которых будет способствовать повышению доходности и привлечению инвестиций в отрасль.

Так на наш взгляд, особый интерес вызывает возможность функционирования агрохолдинга как механизма взаимодействия головной компании и группы филиалов, выступающих от имени и в интересах учредившего их предприятия, то есть возможность регистрации сельскохозяйственных предприятий как филиалов головной компании, не имеющих отдельных организационно-правовых форм собственности, но являющихся обособленными предприятиями [1].

Изучив теоретические основы и законодательство в области налогообложения, следует 


\section{Налоги и налогообложение 6(144) • 2016}

отметить, что функционирование предприятий аграрного сектора по филиальной схеме имеет ряд особенностей. Особое внимание необходимо обратить на то, что при получении статуса филиала головной компании сельскохозяйственное предприятие лишается права на льготное налогообложение, а, следовательно, налоговая нагрузка ложится на данное предприятие в полном объеме. Ответственность за исполнение всех обязанностей по уплате налоговых платежей несет юридическое лицо, в состав которого входит соответствующее обособленное подразделение. Для более глубокого исследования механизма взаимодействия в агрохолдинге считаемы целесообразным рассмотреть особенности налогообложения, документооборота и осуществления хозяйственной деятельности филиала компании [1].

Налог на добавленную стоимость. При реализации через филиал налогоплательщиком является юридическое лицо, НДС платится по месту регистрации головной организации. Работа через филиал вызывает дополнительные сложности, связанные с учетом счетов-фактур. Филиалу необходимо ежемесячно предоставлять в головную организацию книгу покупок и книгу продаж. Дополнительные сложности возникают при нумерации счетов-фактур, оформлении счетов-фактур. Особенности связаны со спецификой заполнения граф Продавец, Адрес, ИНН/КПП продавца, Покупатель, Адрес, ИНН/ КПП покупателя. При неправильном заполнении реквизитов могут возникнуть сложности при получении налоговых вычетов по НДС. Необходимо проводить дополнительную разъяснительную работу с поставщиками по порядку заполнения счетов-фактур, отслеживать правильность их заполнения.

Налог на прибыль организаций. При реализации через филиал налог на прибыль платится как по месту нахождения головной организации, так и по месту нахождения филиала, при этом филиалу передается часть прибыли пропорционально доле стоимости основных средств и фонда оплаты труда филиала в общей стоимости основных средств и фонде оплаты труда организации. Налог на прибыль по месту нахождения филиала уплачивается только в части налога, направляемого в субъекты РФ. Право по уплате налога на прибыль в части филиала может быть передано головной организации.

Налог на имущество организаций. Налог на имущество организаций платится каждым обособленным подразделением, имеющим отдельный баланс и расчетный счет, самостоятельно со стоимости основных средств, которая числится в подразделении.

Налог на доходы физических лиц. Налог на доходы физических лиц платится каждым обособленным подразделением, имеющим отдельный баланс и расчетный счет, самостоятельно с доходов сотрудников по обособленному подразделению. Отчетность по филиалам подается по месту нахождения филиала и по месту нахождения головной организации, причем в части сотрудников филиала - и по месту нахождения филиала, и по месту нахождения головной организации.

Следует отметить, что, являясь структурными подразделениями организаций, филиалы, представительства и иные обособленные подразделения в ряде случаев обязаны исполнять обязанности головных организаций по уплате налогов и сборов по месту своего фактического нахождения. Сами обособленные подразделения не признаются участниками налоговых правоотношений и не имеют статуса налогоплательщиков, налоговых агентов и иных обязанных лиц.

Рассмотрим объем необходимых налоговых платежей в разрезе предприятий и суммарный объем налогового бремени при получении сельскохозяйственными предприятиями статуса филиалов (рис. 1).

Таким образом, наибольший объем налоговых поступлений будет осуществляться за счет уплаты налога на прибыль организаций (34,2 млн руб. в год в целом по обособленным подразделениям сельскохозяйственной направленности), НДС (12,1 млн руб. в год в целом по обособленным подразделениям сельскохозяйственной направленности) и страховых взносов (12,3 млн руб. в год в целом по обособленным подразделениям сельскохозяйственной направленности). Суммарный объем налогового бремени составит 75,2 млн руб. в год в целом по обособленным подразделениям сельскохозяйственной направленности. 


\section{Прогнозирование и планирование в налогообложении}

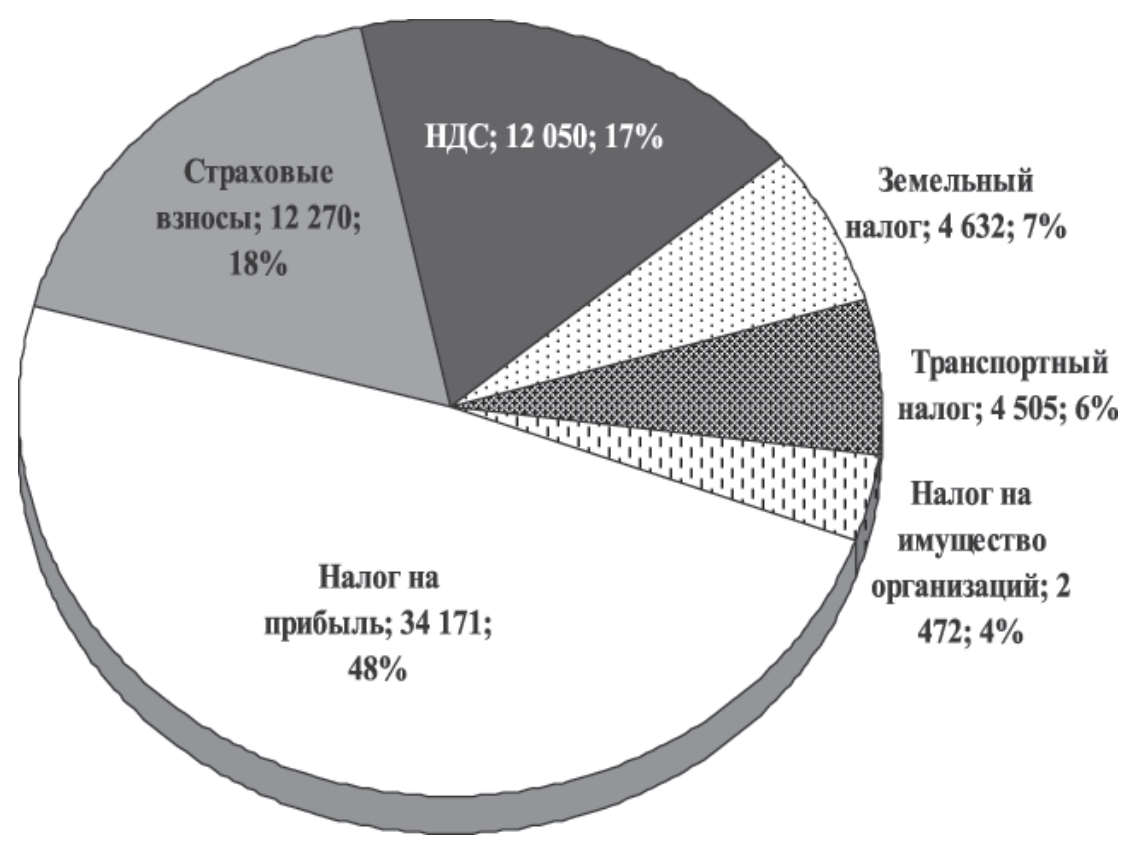

Рис. 1. Величина налоговых платежей, при получении сельскохозяйственными предприятиями статуса филиалов, млн руб., \%

Проведенный сравнительный анализ действующей системы налогообложения и системы налогообложения при получении предприятиями сельского хозяйства статуса филиалов представлен в таблице 1.

Мы видим, что величина налоговой нагрузки головной компании, осталась прежней и составила 8,5 млн руб., при этом ответственность за исполнение всех обязательств по уплате нало- говых платежей возлагается на юридическое лицо, в состав которого входит соответствующее обособленное подразделение, а, следовательно, нагрузка по сопровождению документооборота в большей степени ложится на бухгалтерию головной компании агрохолдинга. Величина налогового бремени по филилалам составляет 75,2 млн руб., что в 1,6 раз выше существующей интенсивности налоговой нагрузки.

Величина налоговых платежей по холдингу при действующей системе налогообложения и при получении сельскохозяйственными предприятиями статуса филиалов

\begin{tabular}{|l|c|c|}
\hline \multicolumn{1}{|c|}{ Показатели } & $\begin{array}{c}\text { Сельскохозяйственные предприятия } \\
- \text { филиалы головной компании }\end{array}$ & $\begin{array}{c}\text { Сельскохозяйственные предприятия } \\
\text { самостоятельные юридические лица }\end{array}$ \\
\hline $\begin{array}{l}\text { Всего налогов в головной компании, } \\
\text { тыс. руб. }\end{array}$ & 8520 & 8520 \\
\hline $\begin{array}{l}\text { Всего налогов по филиалам } \\
\text { (сельскохозяйственные предприятия), } \\
\text { тыс. руб. }\end{array}$ & 75200 & 46855 \\
\hline По холдингу в целом, тыс. руб. & 83720 & 55375 \\
\hline
\end{tabular}




\section{Налоги и налогообложение 6(144) • 2016}

Наряду с этим следует отметить что, одним из негативных последствий перехода на филиальную систему взаимоотношений между головной компанией и обособленным подразделениями является потеря статуса предприятиями статуса «сельхозтоваропроизводителя», а, следовательно, и возможности оформления и получения субсидий из федерального и регионального бюджетов на осуществление производственной деятельности. Таким образом, исследуемым сельскохозяйственным предприятиям, входящим в состав агрохолдинга выгоднее являться самостоятельными юридическими лицами, нежели филиалами.

\section{Библиография}

1. Оробинская И.В. Оптимизация параметров развития производства и налогообложения в интегрированных формированиях АПК: автореф. дисс.... на соиск. канд. экономич. наук // Воронежский государственный аграрный университет им. К.Д. Глинки. Воронеж, 2010. С. 43.

2. Оробинская И.В. Изменение внешней и внутренней политики РФ в отношении сельхозтоваропроизводителей в условиях вступления в ВТО / И.В. Оробинская, А.В. Бурыка // Налоги и налогообложение. 2012. №9-10. С. 30-33.

3. Оробинская И.В. Таможенное регулирование в России после при-соединения к ВТО / А.Г. Казьмин, И.В. Оробинская // Финансы и кредит. 2013. №48(576). С. 46-55

4. Оробинская, И.В. Налоговые инструменты обеспечения стабильного развития отраслей АПК / И.В. Оробинская // Налоги и налогообложение. 2014. №4. С. 501-508

5. Оробинская, И.В. Проблемные аспекты применения НДС предприятиями АПК России / И.В. Оробинская, А.Г. Казьмин // Налоги и финансовое право. 2014. №12. С. 79-84

6. Васильев А.В. Цены,инфляция, налоги, инновационное развитие // Административное и муниципальное право. - 2012. - 3. - С. 64 - 67.

7. Якимкина Н.И., Каланова Н.А. Перспективы развития системы местного налогообложения в Республике Мордовия. // Финансы и управление. - 2015. - 3. - С. 69 - 81. DOI: 10.7256/2409-7802.2015.3.15200. URL: http://www.e-notabene.ru/flc/article_15200.html

8. Мухамадеева Г.А. Соглашение как форма налогового мониторинга // Административное и муниципальное право. - 2015. - 12. - C. 1292 - 1297. DOI: 10.7256/1999-2807.2015.12.16995.

\section{References (transliterated)}

1. Orobinskaya I.V. Optimizatsiya parametrov razvitiya proizvodstva i nalogooblozheniya v integrirovannykh formirovaniyakh APK: avtoref. diss.... na soisk. kand. ekonomich. nauk // Voronezhskii gosudarstvennyi agrarnyi universitet im. K.D. Glinki. Voronezh, 2010. S. 43.

2. Orobinskaya I.V. Izmenenie vneshnei i vnutrennei politiki RF v otnoshenii sel'khoztovaroproizvoditelei $\mathrm{v}$ usloviyakh vstupleniya v VTO / I.V. Orobinskaya, A.V. Buryka // Nalogi i nalogooblozhenie. 2012. №9-10. C. 30-33.

3. Orobinskaya I.V. Tamozhennoe regulirovanie v Rossii posle pri-soedineniya k VTO / A.G. Kaz'min, I.V. Orobinskaya // Finansy i kredit. 2013. №48(576). C. 46-55

4. Orobinskaya, I.V. Nalogovye instrumenty obespecheniya stabil'nogo razvitiya otraslei APK / I.V. Orobinskaya // Nalogi i nalogooblozhenie. 2014. №4. C. 501-508

5. Orobinskaya, I.V. Problemnye aspekty primeneniya NDS predpriyatiyami APK Rossii / I.V. Orobinskaya, A.G. Kaz'min // Nalogi i finansovoe pravo. 2014. №12. C. 79-84

6. Vasil'ev A.V. Tseny,inflyatsiya, nalogi, innovatsionnoe razvitie // Administrativnoe i munitsipal'noe pravo. - 2012. - 3. - C. 64 - 67.

7. Yakimkina N.I., Kalanova N.A. Perspektivy razvitiya sistemy mestnogo nalogooblozheniya v Respublike Mordoviya. // Finansy i upravlenie. - 2015. - 3. - C. 69 - 81. DOI: 10.7256/2409-7802.2015.3.15200. URL: http://www.e-notabene.ru/flc/article_15200.html

8. Mukhamadeeva G.A. Soglashenie kak forma nalogovogo monitoringa // Administrativnoe i munitsipal'noe pravo. - 2015. - 12. - C. 1292 - 1297. DOI: 10.7256/1999-2807.2015.12.16995. 